\title{
Does the London Metal Exchange Follow a Random Walk? Evidence from the Predictability of Futures Prices
}

\author{
Sascha Otto*
}

\author{
Helmut-Schmidt-Universität, Institut für Internationale Finanzierung, Holstenhofweg 85, D-22043 Hamburg, Germany
}

\begin{abstract}
This paper analyses the validity of the weak-form market efficiency, using the random-walk hypothesis for the six industrial base metals - copper, aluminium, zinc, nickel, tin and lead - traded at the London Metal Exchange. I analyse the behaviour of daily and weekly prices of the daily rolling three-month futures contracts, as these contracts exhibit the highest level of trading activity. In contrast to other efficient-market studies, the efficiency of futures prices is not tested as an unbiased predictor of the spot prices but from the predictability of futures prices themselves. I focus on the post-Tin Crisis period of 1989 to 2007. My test methodology includes the Box \& Pierce Q-statistics, variance ratio tests by Lo and MacKinlay with homoscedastic and heteroscedastic test estimates, nonparametric ranks- and signs-based variance ratio tests by Wright and wild bootstrapping variance ratio tests by Kim. My sample basis fails to reject the random-walk hypothesis for all base metal futures except for lead.
\end{abstract}

Keywords: London Metal Exchange, LME, random walk, weak-form efficiency, futures markets, commodities.

\section{INTRODUCTION}

Although the efficient-market hypothesis (EMH) has been extensively tested on different stock exchanges using individual share and index data, most commodity markets have been neglected by recent studies (Moustafa [1]; Rahman and Hossain [2]). Particularly the markets for industrial base metals have been examined only superficially. Notably unexamined until now has been the period after the Tin Crisis (1985-1986), which nearly led to a collapse of the London Metal Exchange (LME). In this paper I analyse the behaviour of daily and weekly prices of the six traded base metals at the London Metal Exchange - copper, aluminium, nickel, zinc, lead and tin - for random walk, implying weak-form market efficiency, as defined by Fama, during the period of 1989 to 2007.

The LME, along with the New York Mercantile Exchange (NYMEX) and the Shanghai Metal Exchange (SHME), is one of the leading commodity exchanges for base metals. In particular, the official fixing after the second morning trading session (2nd Ring) is an often-used price basis for physically settled contracts in the global metalworking industry.

The data employed in this study consists of the prices of the daily rolling three-month futures contract, which has the advantage that it has not been adjusted for potential backwardation or contango market structures. Furthermore, the three-month futures contracts are subject to the highest trading activity level and should be considered the most liquid contracts traded at the LME. In contrast to other efficient-market studies, the efficiency of futures prices is

*Address correspondence to this author at the Helmut-Schmidt-Universität, Institut für Internationale Finanzierung, Holstenhofweg 85, D-22043 Hamburg, Germany; E-mail: sascha.otto@hanse.net not tested as an unbiased predictor of spot prices, as is the usual practice in the literature, but from the predictability of futures prices themselves. As many physical contracts are cleared using the 2nd Ring settlement prices, there is a feasible incentive for metal producers and consumers to manipulate these fixings in their favour. To avoid any potential bias, I use the prices at the time of the NYMEX close as a reference instead.

I try to seek evidence supporting the existence of at least weak-form efficiency. As weak-form theory asserts that successive returns generated by an efficient market will be independent, I evaluate the hypothesis by performing different tests for random walk. The methodology employed includes the Box \& Pierce Q-statistics, variance ratio tests by Lo and MacKinlay with homoscedastic and heteroscedastic test estimates, nonparametric ranks- and signs-based variance ratio tests by Wright and wild bootstrapping variance ratio tests by $\mathrm{Kim}$. I also divide the sample into two separate subsamples to check for structural breaks. As all sample sets are highly nonnormal, I focus on the results of the signs-based variance ratio tests and the wild bootstrapping variance ratio test, as suggested by Kim [3], because these tests are more powerful and robust for nonnormal sample sets with an unknown distribution and heteroscedasticity.

\section{LITERATURE REVIEW}

Since Samuelson [4] and Fama [5] independently formulated the efficient-market hypothesis, it has been extensively applied to empirical studies of financial securities markets. Fama defined an efficient market as one in which prices always "fully reflect" available information. The hypothesis can be tested in various forms. The weakform efficient-market hypothesis defines the available information set as just the security's historical price time series. It has been tested extensively for stock markets using 
autocorrelation tests, tests for random walk, runs tests, tests for seasonal effects and spectral analysis.

There are some studies that have focused on the LME. The majority of these studies focused on the period prior to the Tin Crisis. Furthermore, none of the studies analysed the random-walk hypothesis for all six base metals traded at the LME. Moreover, all studies tested market efficiency of the futures prices as unbiased prediction of the spot prices.

Taylor [6] tested the random-walk hypothesis on spot prices for copper for the period 1966-1978 and for zinc, lead and tin for the period 1970-1978. His results rejected the random-walk hypothesis for all base metals but tin. Goss [7] analysed the relationship of futures and spot prices for the copper, zinc, lead and tin markets during the period 19711978. His results showed a bias of the futures prices for lead and tin.

Bird [8] used filter techniques to test for weak-form efficiency on LME prices for the same metals during the period 1972-1982. His results showed evidence of market inefficiency for copper and and no evidence for tin. Goss [9] applied joint tests for the same metals for the sample period 1966-1984. His results rejected the EMH for copper and zinc, but failed to reject the EMH for lead and tin.

MacDonald and Taylor [10] tested for co-integration for four metals in the LME for the period 1976-1987. They concluded that the copper and lead futures markets could be considered efficient. They rejected the EMH for tin and zinc. Gross [11] examined unvaried LME prices on the mean square error criterion for the period 1983-1984 in order to test the semi-strong EMH for copper and aluminium futures. He provided evidence that the semi-strong EMH cannot be rejected for both base metals.

Moore and Callen [12] analysed the proposition that forward rates are unbiased predictors of future spot rates for base metal prices on the LME for all six base metals between 1985 and 1989. They showed that the long-run speculative efficiency couldn't be rejected.

Lucey [13] examined the daily seasonal patterns in the returns of aluminium, copper, zinc, lead and nickel for the period 1989-2002. His results indicated the existence of daily seasonality, especially the returns of Monday and Thursday.

Kenourgios [14] analysed the LME copper futures contracts with maturities of three and fifteen months for the period 1989-2000. He tested for both long-run and short-run efficiency using co-integration and error correction models. His results suggested that the copper futures market is inefficient.

\section{METHODOLOGY}

\section{The Random-Walk Hypothesis}

The weak-form market efficiency refers to the predictability in time series of prices on the basis of past information. Samuelson demonstrated that the pricegenerating process of a weak-form efficient market should only be affected by the arrival of new information [15]. New information is assumed to appear at random, so prices should follow a random walk. Price changes are not dependent on each other. A simple random-walk process can be defined as:

$P_{t}=P_{t-1}+u_{t}$

where

$\mathrm{P}_{\mathrm{t}}=$ Price at time $\mathrm{t}$

$\mathrm{u}_{\mathrm{t}}=$ error term for time $\mathrm{t}$

As Campbell, Lo and MacKinlay [16] stated, there are three different versions of the random-walk hypothesis, each of them being slightly more stringent. The strongest assumption implies that all error terms $\mathrm{u}_{\mathrm{t}}$ are independent and identically distributed (i.i.d.):

$u_{t} \sim \operatorname{IID}\left(0, \sigma^{2}\right)$

This assumption implies that absolutely no information on price changes can be obtained from the past. I apply homoscedastic variance ratio tests by Lo and MacKinlay and nonparametric variance ratio tests based on ranks by Wright to test the strong version of random-walk hypothesis.

The semi-strong form implies that the distribution of the arrival of news can change over time, but it is still independent:

$u_{t} \sim \operatorname{indep}\left(0, \sigma^{2}\right)$

This form is very difficult to test because every single $u_{t}$ might come from a totally different distribution. I do not test the semi-strong version of the random-walk hypothesis.

The weak form is based on the correlation of the error terms and implies:

$\operatorname{cov}\left(u_{t}, u_{t-k}\right)=0$

This version is especially important, as heteroscedasticity may be a reason for rejecting the strong version of the random-walk hypothesis.

I apply Q-statistics portmanteau tests, heteroscedastic variance ratio tests by Lo and MacKinlay, nonparametric variance ratio tests based on signs by Wright and wild bootstrapping variance ratio tests by Kim to test the weak version of the random-walk hypothesis.

\section{Box-Pierce Q-Statistics}

The Q-statistics portmanteau test developed by Box and Pierce [17] is a possible method for testing a time series for white noise, an uncorrelated sequence of errors, which is also a definition for a weak-form random walk. I use the relative futures price change as a sequence for the sample basis. The Box-Pierce Q-Statistics are calculated as a linear operation of various squared autocorrelations with different time lags, all weighted equally. It can be defined as:

$Q_{m}=n \sum_{k=1}^{m} r_{k}^{2}$

where

$\mathrm{Q}_{\mathrm{m}}=$ Box-Pierce Q-statistic for $\mathrm{m}$ time lags

$\mathrm{m}=$ number of coefficients 
$\mathrm{n}=$ number of observations

$\mathrm{r}_{\mathrm{k}}=$ autocorrelation coefficient for time lag $\mathrm{k}$

To test the validity of the random-walk hypothesis, the $\mathrm{Q}$-statistic is computed for various values of $\mathrm{m}$. For large sample sizes n, Campbell, Lo and MacKinlay [18] showed that the sample autocorrelation coefficients are asymptotically independent and normally distributed.

$\sqrt{n} r_{k} \sim \mathrm{N}(0,1)$

Thus if the price change series is Gaussian distributed, then the $Q$-statistic is distributed like the sum of squares of $\mathrm{m}$ Gaussian random variables. So this statistic is asymptotically distributed as the chi-square distribution with $\mathrm{m}$ degrees of freedom.

The null hypothesis can be defined as:

$H_{0}: Q_{m} \sim \chi_{m}^{2}$

Q-statistics points out any deviation from the null hypothesis of no autocorrelation in any direction, and at all considered time lags depending on the value of $\mathrm{m}$. The selection of $\mathrm{m}$ is critical for the statistical power of the test, as too small values of $\mathrm{m}$ would disregard possible higher order autocorrelation, and too high values of $\mathrm{m}$ would reduce statistical significance. I try to avoid this problem by calculating all Q-statistics for $\mathrm{m}=1$ to $\mathrm{m}=10$, for both daily and weekly observations.

\section{Variance Ratio Tests by Lo and MacKinlay}

The variance ratio tests by Lo and MacKinlay [19] were first proposed to test for a random walk in case of homoscedasticity and later extended to the more general case of an uncorrelated random walk in case of heteroscedasticity. This test utilises data sampled at various frequencies. Lo and MacKinlay [20] demonstrated that variance ratio tests are statistically more powerful than the Box-Pierce Q-statistics. As an important property of a random walk, the variance of its increments is linear in the observed period. Specifically, the variance estimated from the $q$-periods returns should be $q$ times as large as the variance estimated from one-period returns, or:

$\frac{\operatorname{Var}\left(r_{t}^{q}\right)}{\operatorname{Var}\left(r_{t}\right)}=q$

where

$r_{t}^{q}=$ Returns of a sample $t$ for a the period with a length of $q$

$r_{t}=$ Returns of a sample $t$ with one-period length

The variance ratio $V R(q)$ can be defined as:

$\operatorname{VR}(q)=\frac{\operatorname{Var}\left(r_{t}^{q}\right)}{q \operatorname{Var}\left(r_{t}\right)}$

The null hypothesis is therefore:

$H_{0}: \operatorname{VR}(q)=1$
Lo and MacKinlay derived asymptotic standard normal test statistics for their variance ratios. I will use two different test statistics: $z(q)$ in case of homoscedasticity, and $z^{*}(q)$ in case of heteroscedasticity. The first statistic $z(q)$ assumes an i.i.d. error term. The standard normal $z(q)$ test statistic can be computed as:

$$
z(q)=\frac{V R(q)-1}{\sqrt{\varphi(q)}} \approx N(0,1)
$$

where

$\varphi(q)=\frac{2(2 q-1)(q-1)}{3 q(n q)}$

The heteroscedastic test statistic $\mathrm{z}^{*}(\mathrm{q})$ allows us to relax the requirements of i.i.d. increments. Despite the presence of heteroscedasticity, the test statistic $z^{*}(q)$ is still asymptotically standard normal in case of a random walk. It can be defined as:

$z^{*}(q)=\frac{V R(q)-1}{\sqrt{\varphi^{*}(q)}} \approx N(0,1)$

where

$\varphi *(q)=\sum_{j=1}^{q-1}\left[\frac{2(q-j)}{q}\right]^{2} \hat{\delta}(j)$

and

$$
\hat{\delta}(j)=\frac{\sum_{k=j+1}^{n q}\left(P_{k}-P_{k-1}-\hat{\mu}\right)^{2}\left(P_{k-j}-P_{k-j-1}-\hat{\mu}\right)^{2}}{\left[\sum_{k=1}^{n q}\left(P_{k}-P_{k-1}-\hat{\mu}\right)^{2}\right]^{2}}
$$

where

$\hat{\mu}=$ Average return

I use both homoscedastic and heteroscedastic test statistics for aggregation values q of 2, 4, 8 and 16 .

\section{Variance Ratio Tests Using Ranks and Signs by Wright}

Wright [21] introduced alternative variance ratio tests based on ranks and signs. He showed that for some processes his nonparametric variance ratio tests are performing better in rejecting violations of the random-walk hypothesis than the tests recommended by Lo and MacKinlay. He explained the outperformance of ranks- and signs- based tests by the mention of two potential advantages. First, his tests often allow for computing the exact distribution. As it is not necessary to appeal to any asymptotic approximation, size distortions can be neglected. Second, if the sample data is highly nonnormal, tests based on ranks and signs may be more powerful than other variance ratio tests. Formally for the ranks-based tests, let $r\left(r_{t}\right)$ be the rank of the difference of the futures prices $r_{t}$ among $r_{1}, r_{2}, \ldots, r_{T}$. Then, $r_{1 t}$ and $r_{2 t}$ are the ranks of the futures price differences, defined as: 
$r_{1 t}=\frac{\left(r\left(r_{t}-\frac{T+1}{2}\right)\right)}{\sqrt{\frac{(T-1)(T+1)}{12}}}$

$r_{2 t}=\Phi^{-1}\left(\frac{r\left(r_{t}\right)}{T+1}\right)$

where $\Phi^{-1}$ is the inverse of the standard normal cumulative distribution function.

The series $r_{1 t}$ is a simple linear transformation of the ranks, standardised to have a sample mean 0 and a sample variance 1 . The series $r_{2 t}$, known as the inverse normal or van der Warden score, has a sample mean 0 and a sample variance approximately equal to one. The rank series $r_{1 t}$ and $r_{2 t}$ substitute the difference in futures prices $\left(P_{t}-P_{t-q}\right)$ in the definition of the variance ratio test statistic by Lo and MacKinlay $z(q)$ in equation (11), which is written as $R_{1}$ and $R_{2}$ :

$$
\begin{aligned}
& R_{1}=\left(\frac{\frac{1}{T q} \sum_{t=q+1}^{T}\left(r_{1 t}+r_{1 t-1} \ldots+r_{1 t-q}\right)}{\frac{1}{T} \sum_{t=1}^{T} r_{1 t}^{2}}-1\right) * \frac{1}{\sqrt{\varphi(q)}} \\
& R_{2}=\left(\frac{\frac{1}{T q} \sum_{t=q+1}^{T}\left(r_{2 t}+r_{2 t-1} \ldots+r_{2 t-q}\right)}{\frac{1}{T} \sum_{t=1}^{T} r_{2 t}^{2}}-1\right) * \frac{1}{\sqrt{\varphi(q)}}
\end{aligned}
$$

where $\varphi(q)$ is defined in equation (12).

Wright demonstrated that under the assumption that the rank $r\left(r_{t}\right)$ is an unbiased, random permutation of the numbers $1,2, \ldots, T$, the test statistics' distribution can be provided. So the exact sampling distribution of $R_{1}$ and $R_{2}$ may easily be simulated to an arbitrary degree of accuracy, for a given choice of $T$ and $q$. Therefore, the distribution does not suffer from disturbance parameters and the test can be used to construct a test with exact power.

By using the signs of the differences instead of the ranks, it may be possible to apply a variance ratio test that is exact in case of conditional heteroscedasticity. Formally, for a time series $r_{t}$, let $u\left(r_{t}, k\right)=1\left(r_{t}>k\right)-0.5$. Thus $u\left(r_{t}, 0\right)$ is 0.5 if $r_{t} \quad$ is positive and -0.5 otherwise. Let $s_{t}=2 u\left(r_{t}, 0\right)=2 u\left(\varepsilon_{t}, 0\right)$. Clearly, $s_{t}$ is an i.i.d. series with zero mean and variance equal to one. Each $s_{t}$ is equal to 1 with a probability 0.5 and is equal to -1 otherwise. The test statistic based on signs $S_{1}$ is given by:
$S_{1}=\left(\frac{\frac{1}{T q} \sum_{t=q+1}^{T}\left(s_{t}+s_{t-1} \ldots+s_{t-q}\right)^{2}}{\frac{1}{T} \sum_{t=1}^{T} s_{t}^{2}}-1\right) * \frac{1}{\sqrt{\varphi(q)}}$

In Monte Carlo experiments and empirical tests, Wright showed that this test could be exact and more powerful than other variance ratio tests under both homoscedastic and heteroscedastic conditions.

\section{Wild Bootstrapping Variance Ratio Tests by Kim}

Kim [22] proposed variance ratio tests based on wild bootstrapping - a re-sampling method that approximates the sampling distribution of the test statistic. The main advantage of this finite sample test is the fact that it does not rely on asymptotic approximations. Therefore, it is robust to nonnormality. $\mathrm{Wu}$ [23] and Mammen [24] demonstrated that wild bootstrapping should be a natural choice in case of conditional and unconditional heteroscedasticity. The test is based on a Chow and Denning [25] joint version of the Lo and MacKinlay test statistic $z^{*}(q)$, as provided in equation (13), selecting the maximum absolute value from a set of $l$ test statistics. The test statistic can be written as:

$$
M V\left(q_{i}\right)=\max _{1 \leq i \leq l}\left|z^{*}\left(q_{i}\right)\right|
$$

The wild bootstrap variance ratio test can be conducted in three stages, as below:

Form a bootstrap sample of $\mathrm{T}$ observations $a_{t}^{*}=\eta_{t} a_{t},(t=1, \ldots T)$ where $\eta_{t}$ is a random sequence with zero mean and unit variance; a normal distribution is used here.

(ii) Calculate $M V\left(q_{i}\right)$ using $a_{t}^{*}$ from the bootstrap sample generated in stage (i)

(iii) Repeat stages (i) and (ii) $\mathrm{m}$ times, for example, 1.000 times in this paper, to form a bootstrap distribution of the test statistic $M V\left(q_{i}, j\right)_{j=1}^{m}$.

The bootstrap distribution $M V\left(q_{i}, j\right)_{j=1}^{m}$ is used to approximate the sampling distribution of $z^{*}(q)$ given in equation (13). The p-value of the test is calculated as the proportion of $M V\left(q_{i}, j\right)_{j=1}^{m}$ greater than the sample value of $z^{*}(q)$.

In Monte Carlo simulations, Kim demonstrated that wild bootstrapping variance ratio tests are powerful and robust alternatives for testing the random-walk hypothesis.

\section{DATA}

The London Metal Exchange, founded in 1877, is the oldest metal exchange. The LME is the most liquid base metal exchange, with a trading volume of $\$ 9,500$ billion in 2007. It offers 24 -hour trading by the three-stage system of open-outcry during the four "Ring" sessions, where every single metal is traded for a five-minute period, the "LME 
Select" electronic platform and the "Inter-office" telephone market. It provides cash, futures and option contracts for the six base metals with prompts up to 63 months forward. The most liquid and most important contract is the daily rolling three-month futures contract. I will use this contract as a basis to test the random-walk hypothesis. As this contract results in a different prompt date for every trading day, my analysis cannot be used for real-life trading strategies. My random-walk analysis is based on the predictability of futures prices themselves and not on the generation of abnormal profits. The natural choice of data source would be the daily published 2nd Ring settlement prices, which are officially determined by the LME price committee. I will use a different source, based on the fact that these futures settlement prices are the basis of many physical trades. These trades might be a feasible incentive for metal producers and consumers to manipulate these fixings in their favour [26]. To avoid any potential bias, I use the prices at the time of the NYMEX close as reference instead. I study the sample period beginning in June 1987 for aluminium, May 1987 for copper, October 1987 for nickel, January 1988 for zinc, January 1987 for lead and June 1989 for tin. I consider data for all six metals up to October 2007. The time span for sampling of data was chosen by the availability of data. I also check the sample for structural breaks: I divide the sample into sub samples before and after 2000, which roughly coincides with, first, the bull market in equities and weak commodity prices of the 1990s and, second, the period of relatively greater commodity strength after 2000 . Nontrading is not a problem, as all six base metals are highly liquid during the regular trading sessions. The daily relative futures price change is calculated in a manner consistent with prior random-walk tests, as the logarithmic difference of two sequenced prices in a series. The weekly relative futures price changes are calculated on the basis of the logarithmic difference of Monday's closing price (or the next following valid trading day, if Monday is not a valid trading day) and Friday's closing price (or the previous valid trading day, if Friday is not a valid trading day). Fig. (1) presents the daily observations and Fig. (2) the weekly observations of all six base metals. Descriptive statistics of daily observations are summarised in Table $\mathbf{1}$ and of weekly observations in Table 2. I use a long sample period of 20 years to get an adequate sample basis, as I focused on weekly observations. Lo and MacKinlay [27] suggested that weekly data are superior to daily figures because they are free from sampling problems of biases inherent in the daily prices. Chow and Denning [28] showed that the variance ratio tests are superior to other random-walk tests when at least 256 observations are regarded. They also showed that an increasing number of observations improve statistical power. All error terms of the sample sets were tested for normality using the KolgoroffSmirnov and the Jarque-Bera-Tests. I strongly reject the normality assumption for all daily and weekly sample sets. In Monte Carlo experiments, Wright [29, 6] demonstrated important power gains and robustness of his tests, compared with the Lo and MacKinlay tests, especially in case of nonnormality. Moreover, Kim [30] showed that wild bootstrap tests are superior to other variance ratio tests, especially for different error term distributions. He suggested using wild bootstrap tests along with Wright's sign test. I follow his argumentation and put the focus on these tests' results.

\section{RESULTS}

\section{Results from the Box-Pierce Q-Statistics}

Table 3 summarises Q-statistics for daily and Table $\mathbf{4}$ for weekly observations of the six base metal futures. To test the validity of the random-walk null hypothesis, Q-statistics have to be compared to a chi-square distribution with $m$ degrees of freedom. I calculate Q-statistics for $\mathrm{m}=1$ to 10 as a composite measure of autocorrelation for $\mathrm{m}$ lags. For the daily observations, the Q-statistics for aluminium shows no significance at the $5 \%$ level, for all values of $\mathrm{m}$. The Qstatistics for copper, nickel and tin are all significant at a 5\% level, for all values of $\mathrm{m}$, where the main source is the high autocorrelation for the lag of 1 and 2. Noteworthily, the Qstatistics of both zinc and lead are not significant at a $5 \%$ level, for $\mathrm{m}=1$. For values of $\mathrm{m}=2$ to 10 , Q-statistics are significant mainly because of high autocorrelation for a lag of 2 for zinc respectively lag of 2 and 3 for lead.

For the weekly observations, Q-statistics for aluminium confirm the findings, as it shows also no significance at a 5\% level, for all values of $\mathrm{m}$. In contrast to the daily sample, zinc and tin reveal no significance for all values of $\mathrm{m}$. Interestingly, the high autocorrelation for the lag of 1 and 2 is missing, which might indicate that for both metal futures, price changes tend to revert to the mean on a weekly sample basis. Q-statistics for copper are significant for $m=1$, but not for higher values of $\mathrm{m}$. Nickel shows no significance for values of $\mathrm{m}=1$ to 9 , but Q-statistics for $\mathrm{m}=10$ are significant at a $5 \%$ level. In contrast to the daily sample basis, lead shows a high first-order autocorrelation on a weekly sample basis. Consequences are significant Qstatistics for all values of $\mathrm{m}$.

\section{Results from the Variance Ratio Tests by Lo and MacKinlay}

Tables 5 and $\mathbf{6}$ report the test statistics in case of homoscedasticity $\mathrm{z}(\mathrm{q})$ and heteroscedasticity $\mathrm{z}^{*}(\mathrm{q})$ for the six base metal futures. The test statistics are using aggregation values $\mathrm{q}$ ranging from 2 to 16. Table $\mathbf{5}$ represents the results for the daily sample period and Table $\mathbf{6}$ reports similar results for the weekly sample period.

For the daily observations, I fail to reject the randomwalk null hypothesis at a $5 \%$ level of significance for the aluminium and zinc futures under homoscedastic and heteroscedastic assumptions and at all aggregation levels. For the price changes of the copper futures, I reject the random-walk hypothesis for aggregation levels of $q=2$ and $\mathrm{q}=4$ in case of homoscedasticity. Moreover, the rejection is not due to changing variances because the heteroscedastic test result $\mathrm{z}^{*}(\mathrm{q})$ is also significant at a $5 \%$ level for an aggregation level of $q=4$. Nickel futures show significance for all aggregation levels except $q=4$, under heteroscedastic increments. For lead futures, test statistics $\mathrm{z}(\mathrm{q})$ and $\mathrm{z}^{*}(\mathrm{q})$ are significant for aggregation levels $\mathrm{q}=4$ and $\mathrm{q}=8$. For tin, 

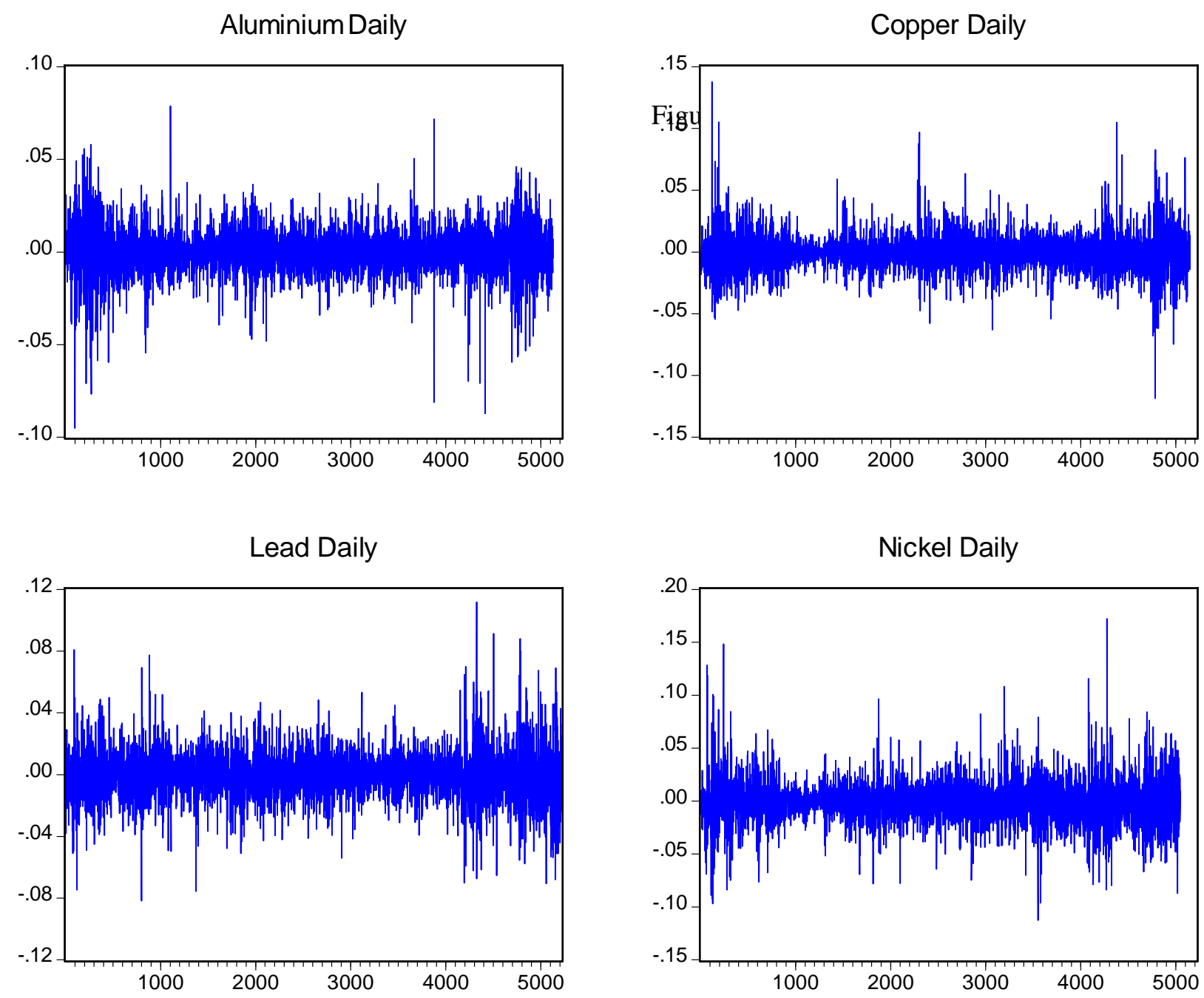

Tin Daily

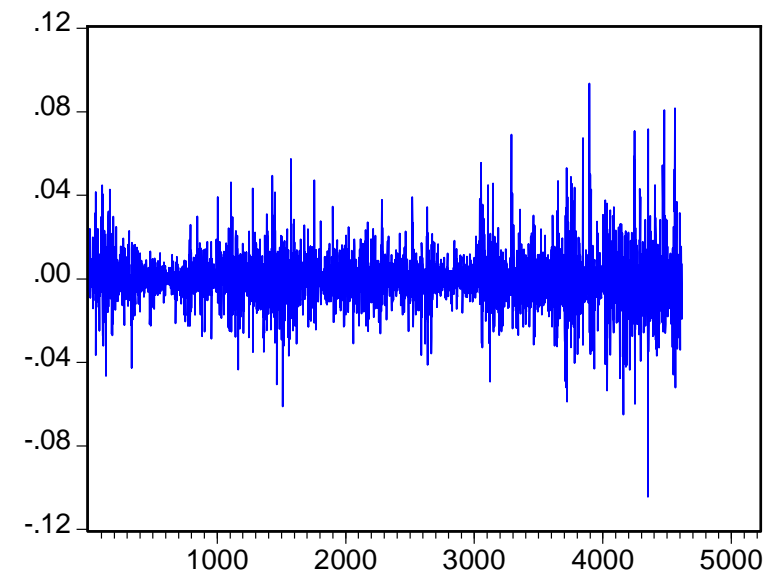

Zinc Daily

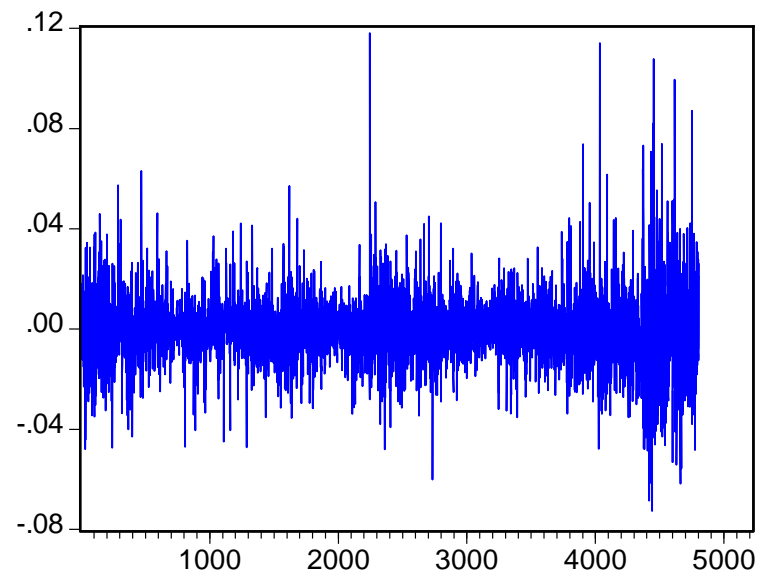

Fig. (1). Daily observations 

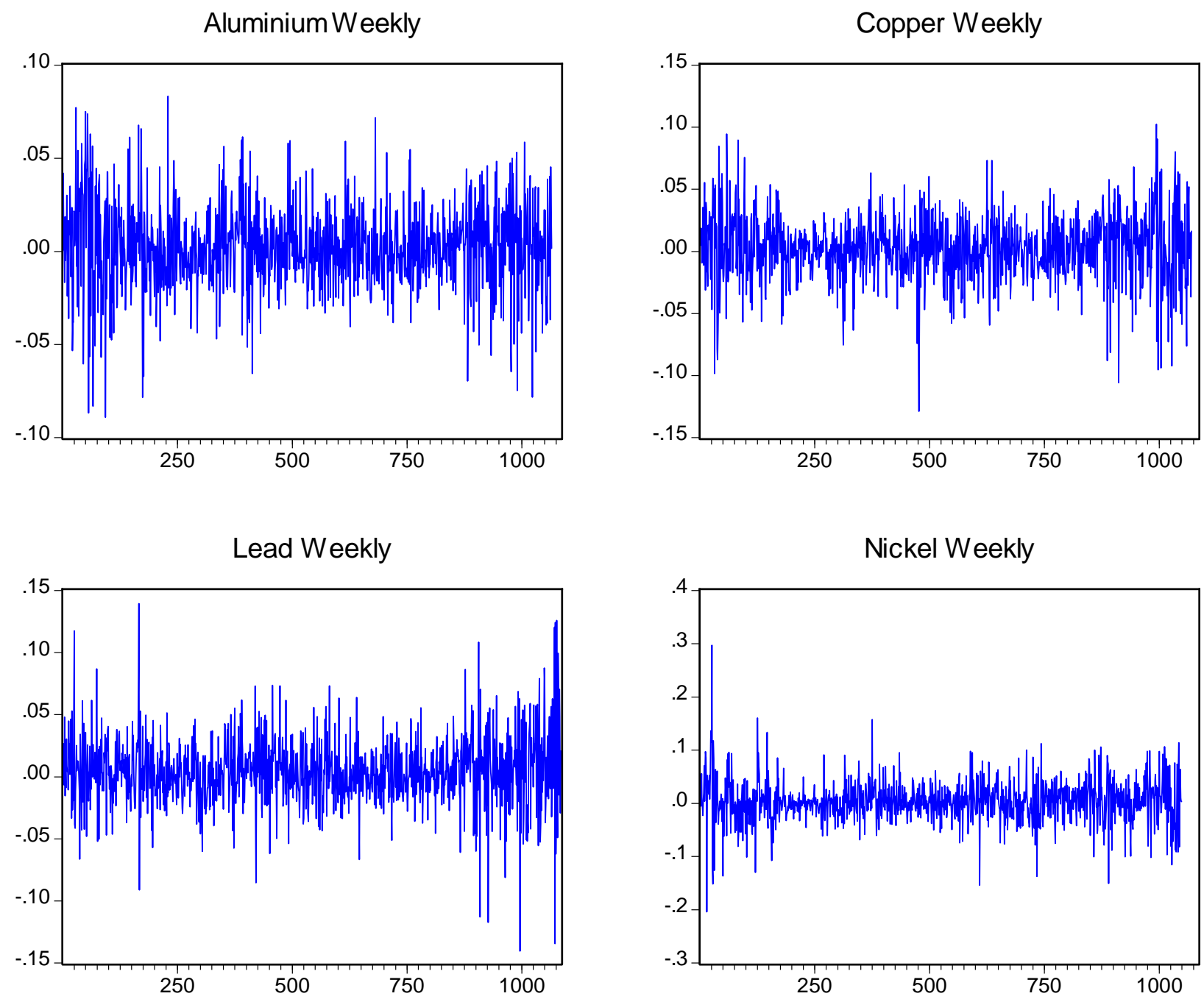

Tin Weekly

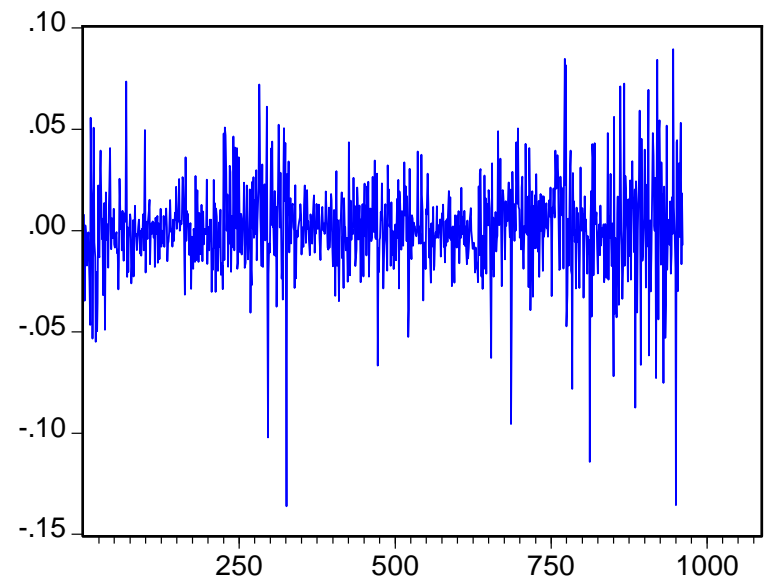

Zinc Weekly

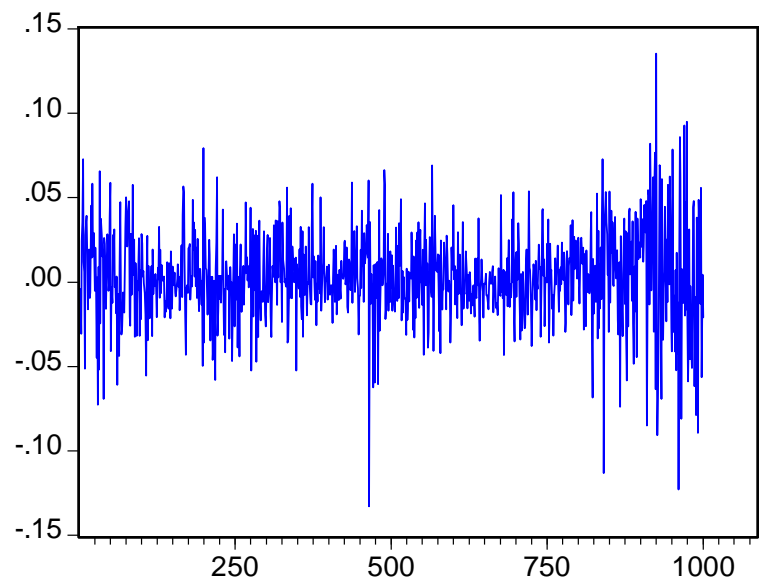

Fig. (2). Weekly obervations. 
Table 1. Descriptive Statistics (Daily)

\begin{tabular}{|c|c|c|c|c|c|c|}
\hline Mean & 0.00010 & -0.00033 & -0.00040 & -0.00036 & -0.00010 & -0.00014 \\
\hline Maximum & 0.07870 & 0.13776 & 0.11170 & 0.17225 & 0.09353 & 0.11801 \\
\hline Minimum & -0.09505 & -0.11852 & -0.08165 & -0.11252 & -0.10434 & -0.07249 \\
\hline Skewness & -0.39783 & 0.48884 & 0.21133 & 0.29348 & 0.28806 & 0.56922 \\
\hline Kurtosis & 7.70340 & 9.39380 & 6.84289 & 8.12467 & 9.99429 & 9.57272 \\
\hline Kolmogorov-Smirnov & 0.48077 & 0.47830 & 0.47648 & 0.46957 & 0.47957 & 0.47893 \\
\hline Probability & 0.00000 & 0.00000 & 0.00000 & 0.00000 & 0.00000 & 0.00000 \\
\hline Observations & 5127 & 5148 & 5216 & 5046 & 4615 & 4805 \\
\hline
\end{tabular}

Table 2. Descriptive Statistics (Weekly)

\begin{tabular}{|c|c|c|c|c|c|c|}
\hline & Aluminium & Copper & Lead & Nickel & Tin & Zinc \\
\hline Mean & 0.002135 & 0.002621 & 0.004429 & 0.00405 & 0.001414 & 0.002939 \\
\hline Median & 0.001787 & 0.003985 & 0.003143 & 0.003361 & 0.001049 & 0.001861 \\
\hline Maximum & 0.083346 & 0.102351 & 0.139488 & 0.297299 & 0.089511 & 0.135418 \\
\hline Minimum & -0.089052 & -0.128749 & -0.140308 & -0.204005 & -0.136192 & -0.132933 \\
\hline Std. Dev. & 0.023031 & 0.027103 & 0.028041 & 0.040033 & 0.022761 & 0.026999 \\
\hline Skewness & -0.061329 & -0.365547 & 0.124052 & 0.212681 & -0.563933 & -0.165251 \\
\hline Kurtosis & 4.188646 & 4.806026 & 6.209926 & 7.767874 & 8.149587 & 5.436854 \\
\hline Kolmogorov-Smirnov & 0.46831 & 0.46450 & 0.46701 & 0.44909 & 0.46649 & 0.46341 \\
\hline Probability & 0.00000 & 0.00000 & 0.00000 & 0.00000 & 0.00000 & 0.00000 \\
\hline Jarque-Bera & 63.36412 & 169.24850 & 468.59250 & 1001.51300 & 1112.77100 & 251.97860 \\
\hline Probability & 0.00000 & 0.00000 & 0.00000 & 0.00000 & 0.00000 & 0.00000 \\
\hline Observations & 1065 & 1070 & 1085 & 1049 & 961 & 1000 \\
\hline
\end{tabular}

only the homoscedastic test statistic is significant at an aggregation level of $q=2$. As these findings are not supported by heteroscedastic results, the reason is not a rejection of the random-walk hypothesis, but time varying variances.

For the weekly observations, aluminium, zinc and tin futures are not significant at all aggregation levels. I found some significant results for copper futures at an aggregation level of $\mathrm{q}=2$ and for nickel futures at aggregation levels of $\mathrm{q}$ $=8$ and $\mathrm{q}=16$, respectively, under the homoscedastic assumption. As these findings are not verified by heteroscedastic test results, the reason is changing variance, and I fail to reject the random-walk hypothesis. For lead, I found significant test statistics $\mathrm{z}(\mathrm{q})$ at aggregation levels of $\mathrm{q}$ $=2, \mathrm{q}=4$ and $\mathrm{q}=8$. These findings are validated by significant heteroscedastic test results for aggregation level $\mathrm{q}$ $=2$ and $\mathrm{q}=4$. Hence I reject the random-walk hypothesis for lead futures, based on weekly observations.

\section{Results from the Variance Ratio Test Using Ranks and Signs by Wright}

Tables 7 and $\mathbf{8}$ summarise the test statistics of the variance ratio tests, using ranks (R1 and R2) and signs (S1). I use aggregation values $q$ ranging from 2 to 16 . Results for the daily sample period are reported in Table 7 and results for the weekly sample period are reported in Table $\mathbf{8}$. 
Table 3. Box-Pierce Q-Statistics (Daily)

\begin{tabular}{|c|c|c|c|c|c|}
\hline Aluminium & 1.72704 & 2.19918 & 3.86433 & 5.540162 & 8.11013 \\
\hline Nickel & 14.53471 & 15.04920 & 16.83735 & 24.31018 & 36.41481 \\
\hline Zinc & 1.822635 & 14.40777 & 14.40812 & 14.98567 & 19.25286 \\
\hline \multirow[t]{2}{*}{ Tin } & 11.23375 & 34.85984 & 40.73144 & 40.91922 & 41.10700 \\
\hline & $\mathbf{Q}_{6}$ & $\mathbf{Q}_{7}$ & $\mathbf{Q}_{8}$ & $\mathbf{Q}_{9}$ & $\mathbf{Q}_{10}$ \\
\hline Aluminium & 9.40203 & 9.51751 & 11.33593 & 11.48987 & 16.17166 \\
\hline Lead & 31.66924 & 31.98901 & 36.75757 & 36.79197 & 37.11181 \\
\hline Tin & 50.11198 & 54.37751 & 56.24777 & 56.31627 & 56.49572 \\
\hline
\end{tabular}

Table 4. Box-Pierce Q-Statistics (Weekly)

\begin{tabular}{|c|c|c|c|c|c|}
\hline & $\mathbf{Q}_{1}$ & $\mathbf{Q}_{2}$ & $\mathbf{Q}_{3}$ & $\mathbf{Q}_{4}$ & $\mathbf{Q}_{5}$ \\
\hline Aluminium & 1.489347 & 1.517528 & 1.6245 & 2.597254 & 2.69287 \\
\hline Nickel & 1.429304 & 1.429326 & 4.726250 & 6.633729 & 6.63605 \\
\hline Zinc & 1.626393 & 2.078699 & 2.196342 & 2.533272 & 2.60226 \\
\hline \multirow[t]{2}{*}{ Tin } & 0.017540 & 4.868548 & 4.883118 & 6.168872 & 8.29225 \\
\hline & $\mathbf{Q}_{6}$ & $\mathbf{Q}_{7}$ & $\mathbf{Q}_{8}$ & $\mathbf{Q}_{9}$ & $\mathbf{Q}_{10}$ \\
\hline Aluminium & 4.19496 & 4.75800 & 7.73817 & 8.92723 & 8.93875 \\
\hline Lead & 16.95870 & 18.05193 & 19.60576 & 20.59478 & 20.64768 \\
\hline Tin & 8.651462 & 8.707496 & 10.49394 & 10.86081 & 10.8798 \\
\hline
\end{tabular}

Bold letters indicate significant value at a $5 \%$ level of significance. Q is the Q-statistics at lag $\mathrm{m}$.

I use ranks tests (R1 and R2) to test random walk in case of homoscedasticity. For the aluminium, zinc and tin futures, using daily observations, the rank-based test results $\mathrm{R} 1$ and R2 failed to reject the random-walk null hypothesis at a 5\% level of significance, for all aggregation levels. For copper, I reject the null hypothesis for the aggregation levels 2,4 and 8 using R1 and for aggregation levels 2 and 4 using R2. For nickel, I reject the null hypothesis for all aggregation levels except 4, using both R1 and R2 test statistics. The randomwalk null hypothesis for lead futures is rejected for aggregation levels 4 and 8, using both R1 and R2. Under heteroscedastic increments, I use the signs-based version of Wright's variance ratio test. For aluminium, nickel and tin futures, the sign-based statistics failed to reject the null hypothesis. For copper, I reject the null hypothesis for all aggregation levels except for 16 . The statistics are also significant at a 5\% level for zinc futures at aggregation levels of 4 and 8, and for lead futures at aggregation levels of 2 and 16. 
Table 5. Variance Ratio Tests by Lo and MacKinlay (Daily)

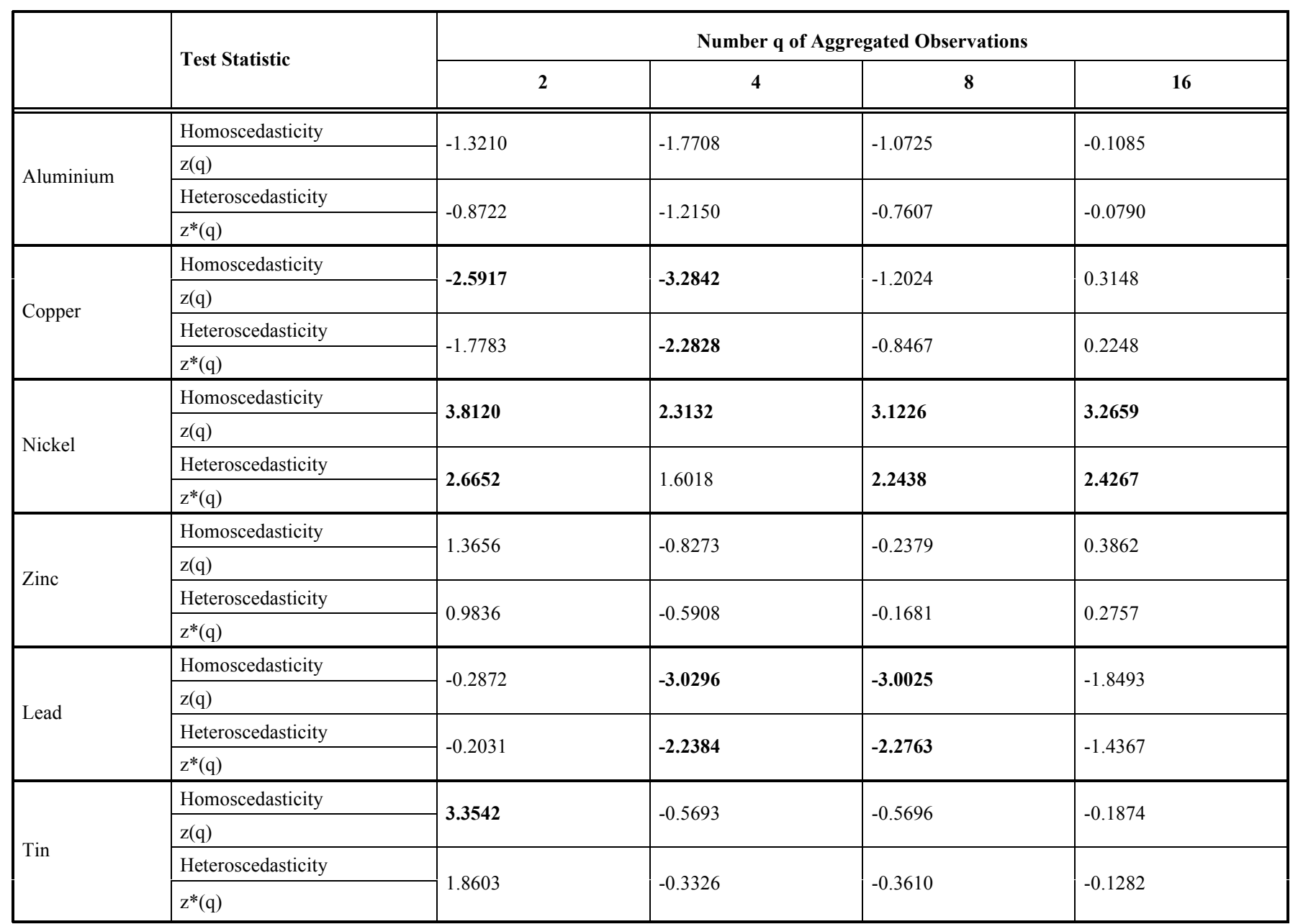

The table shows the test statistics of the variance ratio test for various values of $q . \mathrm{z}(\mathrm{q})$ shows the statistics in case of homoscedasticity and $\mathrm{z}^{*}(\mathrm{q})$ in case of heteroscedasticity, respectively. Bold letters indicate significant value at a $5 \%$ level of significance.

For weekly observations, the ranks-based test statistics are insignificant for aluminium, tin and zinc futures. I found some significant results for copper and nickel futures at aggregation levels 8 and 16, for both R1 and R2 test statistics. For lead, I found significant statistics R1 at an aggregation level of 2 and R2 at aggregation levels of 2 and 4. Under heteroscedastic increments, using signs-based test statistics S1, I failed to reject the null hypothesis for all base metal futures at all levels of aggregation, except for lead. These findings support the already discussed thesis of time varying variances. For lead, I found significant test statistics S1 at aggregation levels of 2 and 4.

The tables show the test statistics R1, R2 and S1 of the variance ratio tests, using ranks and signs by Wright for various values of $\mathrm{q}$. Bold letters indicate significant value at a $5 \%$ level of significance.

The tables show the $p$ values of wild bootstrapping variance ratio tests by Kim, for various values of $q$ and the $p$ value of the joint test statistic MV. Bold letters indicate significant value at a $5 \%$ level of significance.

\section{Results from Wild Bootstrapping Variance Ratio Tests by Kim}

Table 9 summarises the $p$ values for the wild bootstrapping variance ratio tests by Kim for the daily, and Table 10 for weekly, observations of the six base metal futures. I also report the $p$ values of joint test statistic MV. I use aggregation values of $\mathrm{q}$, ranging from 2 to 16 .

For daily observations, I failed to reject the random-walk hypothesis for aluminium, zinc and tin futures for all aggregation levels and the joint test statistic, at a 5\% level of significance. For copper futures, I failed to reject the null hypothesis for the joint test statistic and all aggregation levels except for 4. For nickel and lead, I reject the randomwalk hypothesis, as the joint test statistic is significant. These findings are also supported by the aggregation levels of 2, 8 and 16 for nickel and 4, 8 and 16 for lead.

For weekly observations, I failed to reject the randomwalk hypothesis for all base metal futures except for lead. Lead futures are significant at a $5 \%$ level for the joint test statistic and aggregation levels of 2 and 4. 
Table 6. Variance Ratio Tests by Lo and MacKinlay (Weekly)

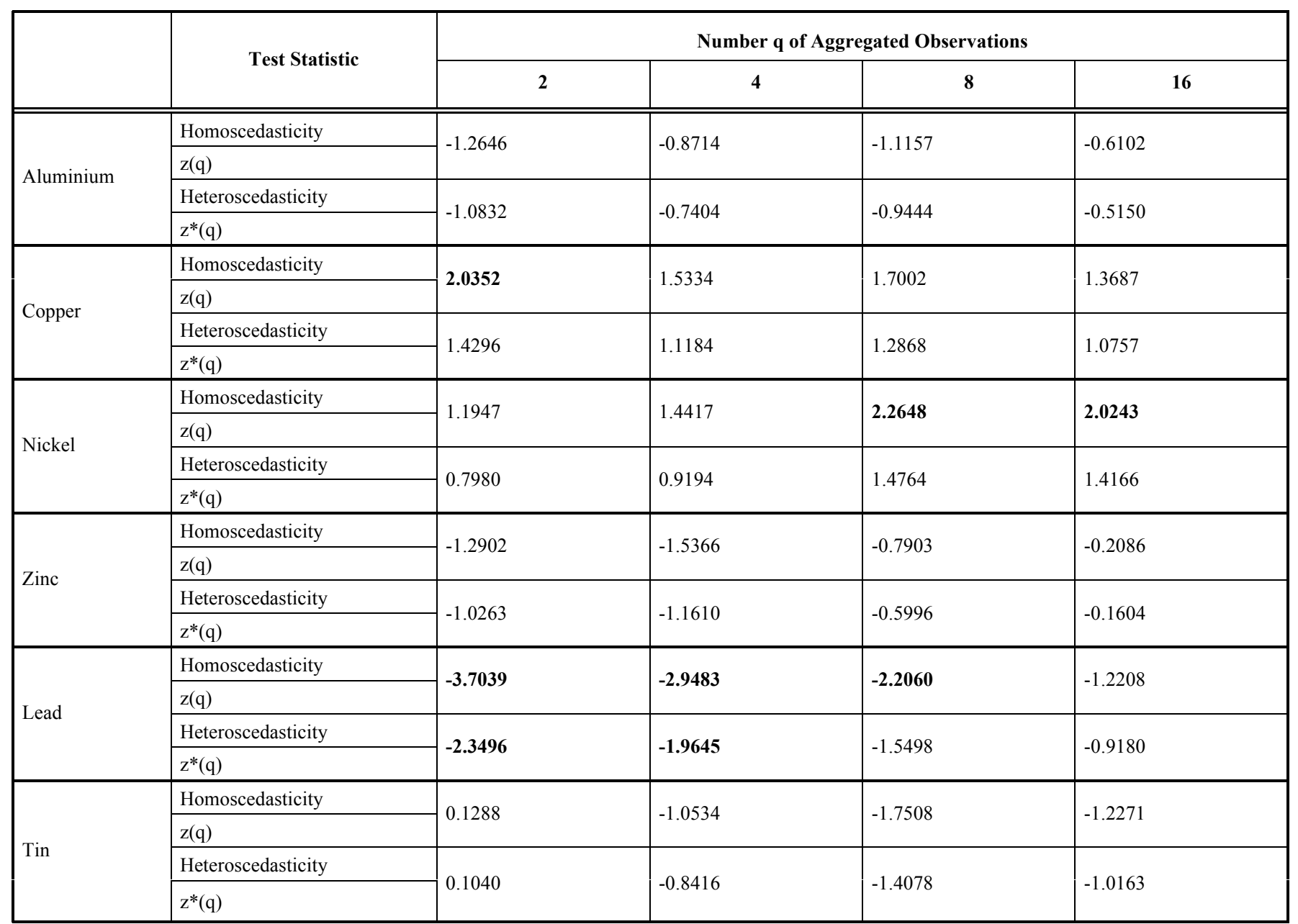

The table shows the test statistics of the variance ratio test for various values of q. $z(q)$ shows the statistics in case of homoscedasticity and $z^{*}(q)$ in case of heteroscedasticity, respectively. Bold letters indicate significant value at a $5 \%$ level of significance.

\section{Results from for Variance Ratio Tests of the Subperiods}

Tables 11-16 summarise the weekly results for the two sub-samples before and after 2000, which roughly coincide with, first, the bull market in equities and weak commodity prices in the 1990s and, second, the period of relatively greater commodity strength after 2000 . For aluminium, zinc and tin, the findings are consistent with the full sample, as all variance ratio tests failed to reject the null hypothesis of random walk. For copper and nickel, some test results indicated a violation of the random-walk hypothesis for the first sub-period. For the second sub-sample, all test statistics except R1 with a lag of 16 failed to reject the random-walk null hypothesis. Therefore, market efficiency might have increased. Interestingly, lead followed a random walk in the first sub-period. In the full sample and the second subperiod, the random-walk hypothesis could be rejected, based on the results of all variance ratio tests. Market efficiency for lead might have reduced in the last decade.

\section{CONCLUSION}

I have tested the random-walk hypothesis to determine the validity of the weak-form market efficiency for the six base metals traded at the LME. I applied Box-Pierce Qstatistics, the variance ratio tests by Lo and MacKinlay, nonparametric ranks- and signs-based variance ratio tests by Wright and wild bootstrapping variance ratio tests by Kim to a sample basis of daily and weekly price differences. As Kim demonstrated, wild bootstrap tests are superior to other variance ratio tests, especially for different error terms distribution and nonnormal samples. I follow his suggestion to use wild bootstrap tests along with Wright's sign tests. Because daily data may suffer from different biases (i.e., bidask spread), I will mainly depend on weekly data for interpretation. Furthermore, I focus on the subsamples to check for structural breaks.

The weekly sample basis accepts the weak-form randomwalk hypothesis for all six base metal futures, except for lead, on the basis of wild bootstrapping variance ratio tests and Wright's sign tests. These findings are also supported by the findings of the Lo and MacKinlay variance ratio tests. Especially for the futures price changes of the aluminium futures, there's a wide-ranging substantiation for the acceptance of the random-walk hypothesis, as all tests failed to reject the null hypothesis at a 5\% level of significance, 
Table 7. Variance Ratio Tests Using Ranks and Signs by Wright (Daily)

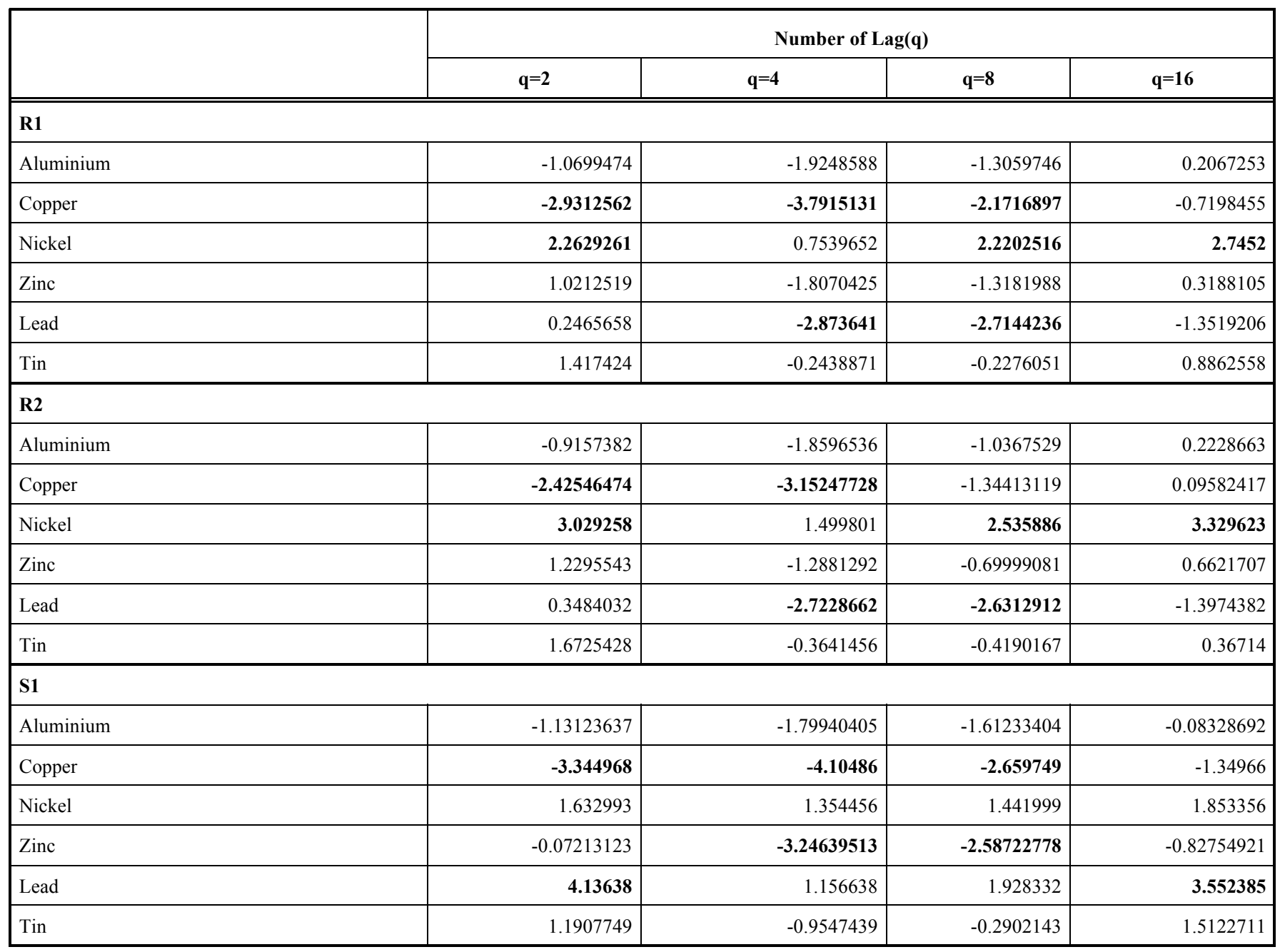

both for daily and weekly observations. These findings are also validated by the analysis of the two subperiods. In contrast, all tests reject the null hypothesis for the daily and weekly returns of the lead futures. Interestingly, in the first sub-period lead prices followed a random walk. By contrast, the results for the second subperiod strongly rejected the random-walk hypothesis. I conclude that the reduction of market efficiency in the second sub-period led to the rejection for the full sample period. For the copper, nickel, zinc and tin futures, I found support for the random-walk hypothesis. This support arises from the fact that none of the weekly returns were significant at a 5\% level. This result is based on the wild bootstrapping MV sample statistics, Wright's sign test and Lo and MacKinlay's test, based on the supposition of heteroscedasticity. As the results of Wright's ranks tests and Lo and MacKinlay's homoscedastic test results for the weekly returns of copper and nickel futures show significance at a 5\% level, I assume changing variances during the sample period. Moreover, market efficiency might have increased because the results for the first sub-period indicated a violation of the random-walk hypothesis, which does not apply for the second sub-period.

My findings are therefore contrary to the findings of Taylor [31], except in the case of lead. Furthermore, the findings disagree with Bird [32], except for the cases of lead and tin. The main reason for the difference might be the different sample period. Both studies focused on the pre-Tin Crisis sample period before 1986. Market regulations were less severe in the pre-Tin Crisis period. Market manipulation and insider trading were not prosecuted. Furthermore, metal price information was not broadly available and was not timely. Consequently, market participants could easily gain an advantage with information that is considered common today. Today acting as a market regulator, the Financial Services Authority monitors the LME to prevent market manipulation. Furthermore, historical and present base metal prices, along with other influential data like open interest and warehouse stocks, are broadly available. Therefore, the market efficiency of the LME might have increased. As nickel and aluminium have not been tested for random walk thus far, I cannot compare the findings with past studies. Due to different methodologies, the findings are only constrictive comparable to other former studies. Furthermore, all other studies regarding market efficiency of the LME implied additional data besides historical prices and should therefore be considered as tests for semi-strong market efficiency.

The results show that even the increase of trading activity by speculative and technically oriented traders like hedge 
Table 8. Variance Ratio Tests Using Ranks and Signs by Wright (Weekly)

\begin{tabular}{|c|c|c|c|c|}
\hline & \multicolumn{4}{|c|}{ Number of $\operatorname{Lag}(q)$} \\
\hline Aluminium & -0.6563807 & -0.3764549 & -0.3916854 & 0.4829192 \\
\hline Copper & 1.872954 & 1.799431 & 2.566385 & 2.705684 \\
\hline Zinc & -0.54087288 & 0.07002319 & 0.84741362 & 1.45044174 \\
\hline Lead & -2.1924377 & -1.1394683 & -0.5215507 & 0.3294378 \\
\hline Tin & 0.146337 & -0.423005 & -0.1871039 & 1.1570874 \\
\hline \multicolumn{5}{|l|}{$\mathbf{R 2}$} \\
\hline Nickel & 1.012839 & 1.75336 & 2.884709 & 3.024175 \\
\hline Zinc & -0.91206343 & -0.73981822 & -0.05588428 & 0.49861672 \\
\hline Lead & -2.7233663 & -1.9860469 & -1.395651 & -0.5733715 \\
\hline Tin & 0.2745905 & -0.6546466 & -0.8471668 & 0.1561416 \\
\hline \multicolumn{5}{|l|}{ S1 } \\
\hline Aluminium & 0.214498 & 1.14654 & 1.341501 & 1.369378 \\
\hline Copper & 0.9782685 & 1.6628545 & 1.673187 & 1.7378365 \\
\hline Nickel & -0.5866321 & 0.5281146 & 1.6909207 & 1.7213044 \\
\hline
\end{tabular}

Table 9. Wild Bootstrapping Variance Ratio Tests by Kim (Daily)

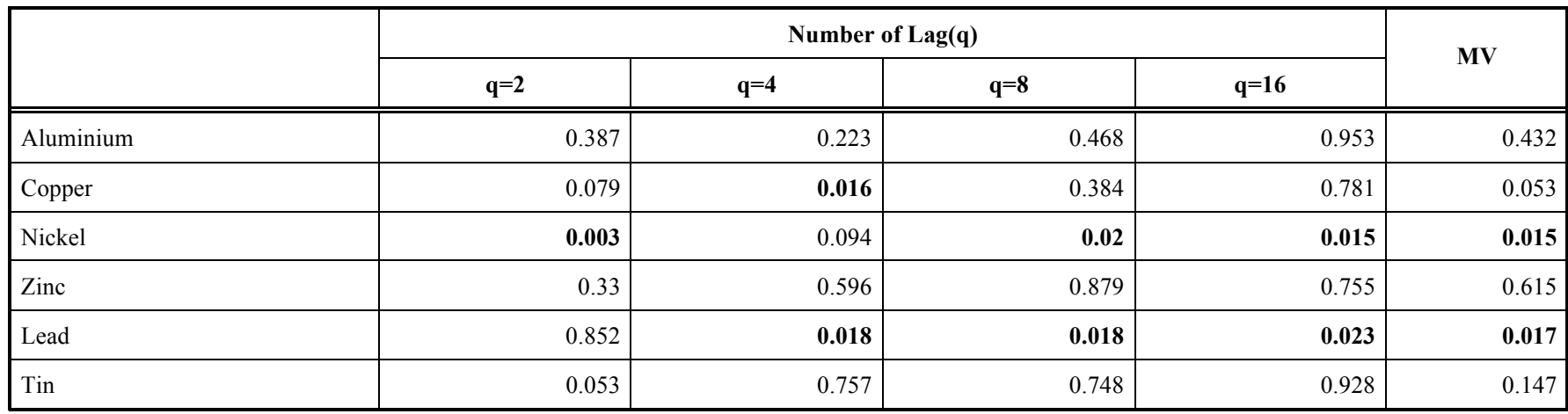

funds did not influence weak-form market efficiency of most base metals traded at the LME.

From an academic point of view, the random-walk test of the LME is especially interesting in reference to the efficient-market hypothesis. As all base metals except for lead follow a random walk, they can be considered weakform efficient. Therefore, it is useless to analyse historical prices in order to forecast future prices. Hence these results support the original efficient-market hypothesis by Fama for base metal commodity markets and should be an interesting contribution to the general discussion of market efficiency and behavioural finance. Further studies regarding market efficiency of the LME should focus on the semi-strong market efficiency. Studies analysing the information content 
Table 10. Wild Bootstrapping Variance Ratio Tests by Kim (Weekly)

\begin{tabular}{|c|c|c|c|c|c|}
\hline & \multicolumn{4}{|c|}{ Number of $\operatorname{Lag}(q)$} & \multirow{2}{*}{ MV } \\
\hline & $q=2$ & $q=4$ & $q=8$ & $q=16$ & \\
\hline Aluminium & 0.321 & 0.508 & 0.367 & 0.622 & 0.59 \\
\hline Copper & 0.136 & 0.257 & 0.189 & 0.234 & 0.319 \\
\hline Nickel & 0.455 & 0.338 & 0.104 & 0.109 & 0.25 \\
\hline Zinc & 0.316 & 0.262 & 0.564 & 0.932 & 0.521 \\
\hline Lead & 0.013 & 0.023 & 0.083 & 0.355 & 0.024 \\
\hline Tin & 0.917 & 0.398 & 0.168 & 0.367 & 0.377 \\
\hline
\end{tabular}

Table 11. Variance Ratios Tests for Subperiods for Aluminium

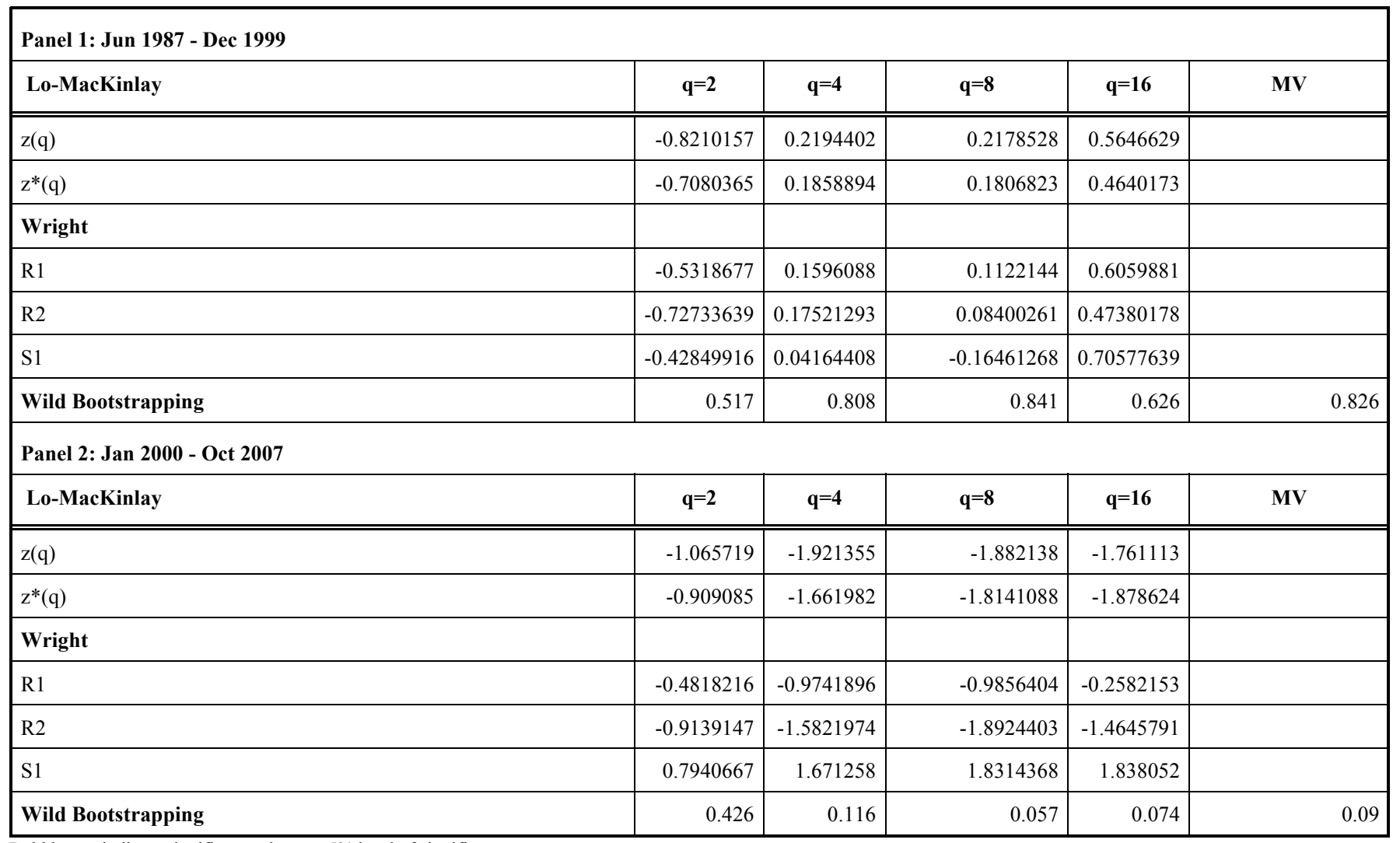

Bold letters indicate significant value at a $5 \%$ level of significance.

of key data, such as warehouse stocks and open interest, might be especially enlightening.

Furthermore, these findings should be especially of interest for hedgers, speculators and market regulators. Hedgers use the LME futures contracts to offset exposure to price fluctuations of an underlying physical metal contract, to minimise the unwanted price risk. Principally, hedgers are interested in an efficient market because prices always fully reflect available information. In the case of a random-walk process, hedgers do not have to take historical futures prices into account for their hedging decisions. Therefore, all base metals, except lead, can be hedged efficiently without considering historical price fluctuations.
Speculators try to generate excess returns by forecasting base metal prices and take a corresponding futures position. Most forecasting systems are based on market inefficiencies and speculators analyse historical base metal prices to establish excess, generating trading strategies. As all threemonth base metals futures except lead follow a random-walk process, they are representing good estimates of intrinsic values and are reflecting the opinion of market participants. Therefore, the returns of speculative base metal positions are independent and unpredictable. Speculators cannot use historical base metal prices to establish trading strategies. In contrast, lead, which has been neglected by speculators in the pre-Tin Crisis period, has become a venture, especially for hedge funds. 
Table 12. Variance Ratios Tests for Subperiods for Copper

\begin{tabular}{|c|c|c|c|c|c|}
\hline Lo-MacKinlay & $\mathbf{q}=\mathbf{2}$ & $q=4$ & $q=8$ & $q=16$ & MV \\
\hline$z(q)$ & 3.335141 & 2.280108 & 2.062499 & 1.216696 & \\
\hline $\mathrm{z}^{*}(\mathrm{q})$ & 2.2289156 & 1.6391012 & 1.5643271 & 0.9691321 & \\
\hline \multicolumn{6}{|l|}{ Wright } \\
\hline R1 & 2.021203 & 1.426938 & 1.7827 & 1.484512 & \\
\hline R2 & 2.684902 & 1.841207 & 1.877428 & 1.384737 & \\
\hline S1 & 0.2328452 & 0.3318959 & 0.79372 & 0.7978912 & \\
\hline Wild Bootstrapping & 0.017 & 0.099 & 0.11 & 0.294 & 0.065 \\
\hline \multicolumn{6}{|c|}{ Panel 2: Jan 2000 - Oct 2007} \\
\hline Lo-MacKinlay & $q=2$ & $q=4$ & $q=8$ & $q=16$ & MV \\
\hline$z(q)$ & -0.5972639 & -0.2061396 & 0.258276 & 0.6556939 & \\
\hline$z^{*}(q)$ & -0.4524579 & -0.1547324 & 0.1972922 & 0.5135722 & \\
\hline \multicolumn{6}{|l|}{ Wright } \\
\hline R1 & 0.339061 & 0.9968891 & 1.6221034 & 2.1306909 & \\
\hline R2 & -0.08878395 & 0.39298741 & 0.98475317 & 1.40970458 & \\
\hline $\mathrm{S} 1$ & 1.1911 & 1.573207 & 1.660601 & 1.783834 & \\
\hline Wild Bootstrapping & 0.695 & 0.895 & 0.836 & 0.565 & 0.875 \\
\hline
\end{tabular}

Table 13. Variance Ratios Tests for Subperiods for Nickel

\begin{tabular}{|c|c|c|c|c|c|}
\hline Lo-MacKinlay & $q=2$ & $q=4$ & $q=8$ & $q=16$ & MV \\
\hline$z(q)$ & 1.202709 & 1.456086 & 2.118585 & 1.732237 & \\
\hline$z^{*}(q)$ & 0.6744475 & 0.7838177 & 1.1801139 & 1.0612362 & \\
\hline \multicolumn{6}{|l|}{ Wright } \\
\hline $\mathrm{R} 1$ & -0.32754 & 0.4250585 & 1.6078637 & 2.1011732 & \\
\hline $\mathrm{R} 2$ & 0.4676345 & 1.0336572 & 2.1184506 & 2.3342587 & \\
\hline S1 & -1.6168822 & -1.201532 & -0.266637 & 0.4345256 & \\
\hline Wild Bootstrapping & 0.528 & 0.44 & 0.211 & 0.202 & 0.448 \\
\hline \multicolumn{6}{|c|}{ Panel 2: Jan 2000 - Oct 2007} \\
\hline Lo-MacKinlay & $q=2$ & $q=4$ & $q=8$ & $q=16$ & MV \\
\hline$z(q)$ & 0.4046801 & 0.4233706 & 0.8351621 & 0.9395991 & \\
\hline$z^{*}(q)$ & 0.3877433 & 0.3789734 & 0.7346946 & 0.8302097 & \\
\hline \multicolumn{6}{|l|}{ Wright } \\
\hline $\mathrm{R} 1$ & 0.5570274 & 1.3412206 & 1.7850327 & 1.8426249 & \\
\hline R2 & 0.5145777 & 0.8061596 & 1.1720264 & 1.182444 & \\
\hline S1 & 0.9925833 & 1.1222324 & 1.4495472 & 1.6455909 & \\
\hline Wild Bootstrapping & 0.711 & 0.707 & 0.396 & 0.347 & 0.628 \\
\hline
\end{tabular}


Table 14. Variance Ratios Tests for Subperiods for Zinc

\begin{tabular}{|c|c|c|c|c|c|}
\hline Lo-MacKinlay & $q=2$ & $q=4$ & $q=8$ & $q=16$ & MV \\
\hline $\mathrm{z}(\mathrm{q})$ & -1.4194891 & -0.501723 & -0.180906 & -0.2049653 & \\
\hline$z^{*}(q)$ & -1.1868918 & -0.4374617 & -0.1649377 & -0.191621 & \\
\hline \multicolumn{6}{|l|}{ Wright } \\
\hline R1 & -0.944128763 & -0.178139682 & 0.141703915 & 0.001102306 & \\
\hline $\mathrm{R} 2$ & -1.10137124 & -0.22746573 & 0.06810524 & -0.08562153 & \\
\hline $\mathrm{S} 1$ & -1.1488539 & -0.7456786 & -0.8391858 & -1.067312 & \\
\hline Wild Bootstrapping & 0.245 & 0.698 & 0.916 & 0.931 & 0.465 \\
\hline \multicolumn{6}{|c|}{ Panel 2: Jan 2000 - Oct 2007} \\
\hline Lo-MacKinlay & $q=2$ & $q=4$ & $q=8$ & $q=16$ & MV \\
\hline$z(q)$ & -0.5778571 & -1.5471504 & -0.8496695 & -0.1119112 & \\
\hline$z^{*}(q)$ & -0.4716823 & -1.1522514 & -0.618373 & -0.0832666 & \\
\hline \multicolumn{6}{|l|}{ Wright } \\
\hline R1 & 0.07809423 & 0.04549748 & 0.85291534 & 1.28727299 & \\
\hline $\mathrm{R} 2$ & -0.2536675 & -0.7972251 & -0.1236843 & 0.6568421 & \\
\hline $\mathrm{S} 1$ & 0.1985167 & 0.5040302 & 1.3589954 & 1.7689605 & \\
\hline Wild Bootstrapping & 0.673 & 0.268 & 0.538 & 0.973 & 0.539 \\
\hline
\end{tabular}

Table 15. Variance Ratios Tests for Subperiods for Lead

\begin{tabular}{|c|c|c|c|c|c|}
\hline \multicolumn{6}{|c|}{ Panel 1: Jun 1989 - Dec 1999} \\
\hline$z^{*}(q)$ & -0.7926261 & -0.7852637 & -0.5255211 & -0.1929942 & \\
\hline \multicolumn{6}{|l|}{ Wright } \\
\hline $\mathrm{R} 2$ & -1.0283987 & -0.5866297 & -0.2411246 & 0.1476666 & \\
\hline S1 & 0.5756472 & 0.7179582 & 1.187086 & 1.3862494 & \\
\hline Wild Bootstrapping & 0.481 & 0.481 & 0.625 & 0.908 & 0.774 \\
\hline \multicolumn{6}{|c|}{ Panel 2: Jan 2000 - Oct 2007} \\
\hline$z^{*}(q)$ & -2.341566 & -1.8949 & -1.563057 & -1.090845 & \\
\hline \multicolumn{6}{|l|}{ Wright } \\
\hline R1 & -2.4630988 & -2.4630988 & -1.4374042 & -0.7077112 & \\
\hline R2 & -2.790994 & -2.301453 & -1.792485 & -1.130328 & \\
\hline S1 & -2.2903583 & -0.9550046 & -0.2348881 & 0.4989183 & \\
\hline Wild Bootstrapping & 0.012 & 0.023 & 0.144 & 0.417 & 0.021 \\
\hline
\end{tabular}


Table 16. Variance Ratios Tests for Subperiods for Tin

\begin{tabular}{|c|c|c|c|c|c|}
\hline \multicolumn{6}{|c|}{ Panel 1: Jun 1989 - Dec 1999} \\
\hline$z^{*}(q)$ & 1.03816358 & -0.02914069 & -0.9811232 & -0.87461521 & \\
\hline \multicolumn{6}{|l|}{ Wright } \\
\hline R2 & 0.94279904 & -0.08531689 & -1.04226281 & -0.69282623 & \\
\hline S1 & 0.2122382 & -0.6579873 & -1.2269182 & -0.5183357 & \\
\hline Wild Bootstrapping & 0.3 & 0.933 & 0.385 & 0.478 & 0.597 \\
\hline \multicolumn{6}{|c|}{ Panel 2: Jan 2000 - Oct 2007} \\
\hline$z^{*}(q)$ & -0.6171293 & -1.0741849 & -1.0758664 & -0.7191189 & \\
\hline \multicolumn{6}{|l|}{ Wright } \\
\hline R1 & -0.340576 & -0.3409254 & 0.6114358 & 1.6166937 & \\
\hline R2 & -0.4124398 & -0.8346093 & -0.3186611 & 0.582174 & \\
\hline S1 & -1.58813333 & -0.07958372 & 1.68616092 & 1.90410932 & \\
\hline Wild Bootstrapping & 0.56 & 0.318 & 0.362 & 0.602 & 0.593 \\
\hline
\end{tabular}

Bold letters indicate significant value at a $5 \%$ level of significance.

Market regulators observe base metal futures prices in order to find evidence of market manipulation and insider trading. An inefficient market complicates the monitoring because regulators cannot verify precisely the occurrence of market manipulation, as any market anomaly might be based on the market inefficiency. As the base metals except lead traded at the LME, follow a random walk, the monitoring of market manipulation and insider trading is unproblematic.

\section{REFERENCES}

[1] Moustafa M. Testing the weak-form efficiency of the United Arab Emirates stock market. Int J Bus 2004; 9: 309-25.

[2] Rahman S, Hossain F. Weak-form efficiency: testimony of dhaka stock exchange. J Bus Res 2006; 8: 1-12.

[3] Kim HK. Wild bootstrapping variance ratio tests. Econ Lett 2006; 92: 38-43.

[4] Samuelson P. Proof that properly anticipated prices fluctuate randomly. Ind Manage Rev 1965; 6: 41-9.

[5] Fama E. Efficient capital markets: a review of theory and empirical work. J Finance 1970; 25: 383-417.

[6] Taylor SJ. Conjectured models for trends in financial prices, tests and forecasts". J R Stat Soc 1980; 143: 338-62.

[7] Goss BA. The forward pricing function of the london metal exchange. App Econ1981; 13: 133-50.

[8] Bird P. The weak form efficiency of the london metal exchange. Appl Econ 1985; 17: 571-81.

[9] Goss BA. The forward pricing function of the london metal exchange. In. Goss BA: futures markets: their establishment and performance, London 1985, pp.157-73.

[10] MacDonald R, Taylor MP. Metal prices, efficiency and cointegration: some evidence from the LME. Bull Econ Res 1988; 40: 235-39.

[11] Gross M. A semi-strong test of the efficiency of the aluminium and copper markets at the LME. J Futures Mark 1988; 8: 67-77.
[12] Moore MS, Callen U. Speculative efficiency on the london metal exchange. The Manchester School 1995; 63: 235-56.

[13] Lucey BM. Daily seasonality in LME base metal returns 19892002: a robust analysis. Working Paper 2003, http://ssrn.com/abstract=368301.

[14] Kenourgios DF. Testing efficiency of the copper futures market: new evidence from london metal exchange. Glob Bus Econ Rev 2004: 261-71.

[15] Samuelson P. Proof that properly anticipated prices fluctuate randomly. Ind Manage Rev 1965; 6: 41-49.

[16] Campbell JY, Lo AW, MacKinlay AC. The econometrics of financial markets. Princeton University Press, Princeton 1997.

[17] Box GEP, Pierce DA. Distribution of residual autocorrelation in autoregressive-integrated moving average time series models. J Am Stat Assoc 1970; 65: 1509-26.

[18] Campbell JY, Lo AW, MacKinlay AC. The econometrics of financial markets. Princeton University Press, Princeton 1997.

[19] Lo AW, MacKinlay AC. Stock market prices do not follow random walks: evidence from a simple specification test. Rev Financ Stud 1988; 1: 41-66.

[20] Lo AW, MacKinlay AC. The size and the power of the variance ratio test in finite samples: a monte carlo investigation. J Econom 1989; 40: 203-38.

[21] Wright JH. Alternative variance-ratio tests using ranks and signs. J Bus Econ Stat 2000; 18: 1-9.

[22] Kim HK. Wild bootstrapping variance ratio tests. Econ Lett 2006; 92: 38-43.

[23] Wu CFJ. Jackknifem bootstrap and other resampling methods in regression-analysis-discussion. Ann Stat 1986; 14: 1261-95.

[24] Mammen E. Bootstrap and wild bootstrap for high-dimensional linear- models. Ann Stat 1993; 21: 255-85.

[25] Chow KV, Dennin K. A simple multiple variance ratio test. J Econom 1992; 58: 385-40.

[26] Gilbert CL. Manipulation of metals futures: lessons learned from Sumitomo. Discussion Paper No. 1537, Centre for Economic Policy Research 1996. 
[27] Lo AW, MacKinlay AC. Stock market prices do not follow random walks: evidence from a simple specification test. Rev Financ Stud 1988; 1: 41-66.

[28] Chow KV, Denning KC. A simple multiple variance ration test. J Econom 1993; 58: 385-401.

[29] Wright JH. Alternative variance-ratio tests using ranks and signs. J Bus Econ Stat 2000; 18: 1-9.
[30] Kim HK. Wild bootstrapping variance ratio tests. Econ Lett 2006; 92: 38-43.

[31] Taylor SJ. Conjectured models for trends in financial prices, tests and forecasts. J R Stat Soc 1980; 143: 338-62.

[32] Bird P. The weak form efficiency of the london metal exchange. Appl Econ 1985; 17: 571-81.

(C) Sascha Otto; Licensee Bentham Open.

This is an open access article licensed under the terms of the Creative Commons Attribution Non-Commercial License (http://creativecommons.org/licenses/by$\mathrm{nc} / 3.0 /$ ) which permits unrestricted, non-commercial use, distribution and reproduction in any medium, provided the work is properly cited. 